\title{
Interrelationships and horizontal strategy to achieve synergy and competitive advantage in the diversified firm
}

Prescott C. Ensign

University of Western Ontario, London, Ontario, Canada

The author thanks Will Acar, Nick Bontis, and Gretchen Schoenfield for helpful comments and discussion. Support from the Foundation for Educational Exchange between Canada and the USA, Institute of International Education, and J.M. Smucker Co. is greatly appreciated.

Ensign, P.C. (1998) Interrelationships and Horizontal Strategy to Achieve Synergy and Competitive Advantage in the Diversified Firm. Management Decision. 36(10): 657-668. doi: $10.1108 / 00251749810245318$ 
Discusses how interrelationships can be developed for synergy. Also focuses on horizontal strategy as a way to achieve competitive advantage. Organizational context can determine a firm's motivation and ability to develop interrelationships that result in overall competitive advantage. Corporate strategy must move beyond the idea that the primary way of creating synergy is the combination of related businesses (by buying and selling businesses). Corporate strategy must focus on creating value that is independent of business unit value. This means developing horizontal strategies that have the objective of coordinating activities and developing programs that encourage the sharing of resources and skills. An understanding of the horizontal organization helps to emphasize that organizational structure and processes are significant in developing interrelationships with the potential to reach the goals of synergy and competitive advantage.

\section{INTRODUCTION}

As firms face increased competition, the need for competitive advantage intensifies. A diversified firm has a number of advantages because it is a multi-business/multi-product organization. One of these, described by Porter (1985), is the potential to develop interrelationships because of the different businesses or products that exist in the firm. This is similar to the advantage available to the multinational firm that is based on managing activities in geographically dispersed units as a coordinated multinational network (Kogut, 1983). In both cases, coordination is an option available to the firm because it is diversified or multinational.

Ansoff $(1965 ; 1988)$ described the combined effect available to a diversified firm as synergy. He suggested that synergy can produce a combined return on resources that is greater than the sum of individual parts. This has been expressed as $2+2=5$ to illustrate that the firms combined performance may be greater than the simple aggregate of parts. Hofer and Schendel (1978, p. 25) referred to synergy as "joint effects". The development of interrelationships is suggested as a way to obtain synergy.

Chakravarthy and Lorange (1991) see adapting the strategy process to the context of the organization as an important management task. This includes nurturing strategic thinking and promoting intrafirm cooperation. According to Chakravarthy and Lorange, synergy describes how - by sharing capabilities - each cooperating entity strengthens each of their competitive positions. Such efforts may be seen as "co-managed strategies" which result in a "systemic solution" (Chakravarthy and Lorange, 1991, p. 22). For example, within Hewlett-Packard, R\&D strategies may be common to several business units. Such shared purpose serves to avoid costly duplication of efforts, i.e. redundant research or "reinvention". To facilitate exchange between business units, Hewlett-Packard utilizes a standardized infrastructure. Communication is enhanced through the use of a highly accessible computer platform. It is important to note that though a system may be flexible and ever-evolving, it must be consciously designed with procedures to promote collaboration (create value) between activities.

Although synergy has been used as a justification for why the firm chooses to diversify, the overall failure rate of diversifications seems to indicate that positive joint effects may not always be achieved. In the firms Porter (1987) studied, for example, more than 50 percent of the diversifications that occurred before 1975 were divested or sold by 1987 . Other researchers have found similar patterns. Because the hoped for synergy may not be achieved (Nayyar, 1992), it is important for managers to have a better understanding of interrelationships in order to increase the probability of achieving synergy.

Success in resource sharing depends on two things. First, it depends on the selection of activities where resource sharing (interrelationships) will occur. This is important because the potential benefits from resource sharing can vary in different organizational contexts. Recognizing the costs and benefits to specific circumstances is important; knowing when not to pursue interdependencies may be as crucial as knowing when to seek them.

Second, the realization of potential opportunities depends on how effectively linkages between activities are actually managed. That is, just because an opportunity exists does not mean that it may be possible to fully develop it or bring it to fruition.

This paper focuses on the interrelationships that can be developed in the diversified firm. It emphasizes horizontal strategy as a way to achieve competitive advantage. A planning process must be used to identify those interrelationships that have the greatest potential for success. The selection of the most critical linkages is important because the organizational costs of coordination are high.

\section{BACKGROUND}

Most research efforts have focused on trying to identify the factors that can explain diversification. In a number of studies, the concept of synergy has been used to identify the relationship between diversification and success 
(Hill and Hoskisson, 1987). More recent studies have tested relatedness and resource sharing in order to understand the joint effects (synergy) in a diversified firm (Davis et al., 1992). Overall, however, there is a significant lack of research that examines interrelationships that can result in competitive advantage for the diversified firm.

It quickly becomes apparent that widespread agreement on the subject matter of this paper will not be immediately forthcoming. For instance, as Kay (1982) equates economies of scope with synergy - marrying the concept of synergy with transaction cost analysis-he indicates that economies of scope provide satisfactory explanation for diversification. Teece (1980), however, argues that economies of scope cannot provide satisfactory rationale for diversification. If one expects that this paper will unlock the secret of developing interrelationships to achieve synergy, and reveal the magic formula to create a horizontal strategy for competitive advantage, then disappointment will surely follow. It is hoped that this paper will provide the necessary first steps and a few tools to reach these goals.

\section{Conceptualizing synergy}

Ansoff $(1965 ; 1988)$ suggested the importance of the concept of synergy to strategic management. It is interesting to note that there are almost no changes in Ansoff 's ideas on synergy from 1965 to 1988. From one perspective he viewed synergy as: "one of the major components of the firm's product-market strategy. It is concerned with the desired characteristics of fit between the firm and its new product-market entries" (Ansoff, 1965, p. 75). This view suggests that synergy is basically a fit between units. Most research studies have used the concept of synergy in this way.

Although Ansoff (1988) reported that synergy (fit) is important in the initial decision to diversify, he also suggests another way to understand synergy. It is clear that he understands how and where synergy can actually occur. He describes four types of synergy based on the components of the ROI (return on investment) formula. Each type of synergy depends on the existence of some common factors between constituent elements (or product markets):

1) Sales synergy - when products use common sales administration, distribution channels, advertising, sales promotion, or reputation.

2) Operating synergy - results from higher utilization of facilities and personnel, spreading of overhead, advantages of common learning curves, or common inputs.

3) Investment synergy - results from the joint use of plant, carryover in research and development, common machinery, tooling, or raw materials.

4) Management synergy - carryover of managerial ability in strategic, organizational, and operating problems.

Although there can be positive joint effects, Ansoff suggests that the synergy hoped for and the synergy actually achieved may be quite different. The result can even be negative $(2+2=3)$.

In the past, the concept of synergy has been narrowly defined and measured in research efforts. In the management literature, synergy has generally been used to mean an overall fit or congruence between units. More recently, a few studies have examined the joint effects between activities rather than entire business units. Joint effects between activities (in the value chain) will be the focus of this study.

\section{Diversification, performance and synergy}

In the 1960s and 1970s, firms were looking for new ways to achieve growth. Diversification was viewed as a way to survive when sales and profitability were declining. As a result, it is easy to understand why Ansoff 's ideas were used as justification by firms as they diversified. It may also explain why most of the research work on synergy has focused on diversifications, mergers, and acquisitions.

As competitors added more businesses, diversification was often viewed as a way to match them. Firms diversified to match leaders in the industry. In many cases, the decisions may have been based on necessity (an effort to ensure the survival of the firm) rather than choice (the result of a well-thought through process). Decisions did not always result in a successful diversification. The question asked was: what are the factors which may account for success or failure?

A number of research efforts have attempted to find answers and explain the behavior of diversified firms. The research studies of Rumelt (1974) resulted in a comprehensive examination of diversified firms. He found different diversification patterns in the firms he studied. He suggested specific categories and classifications to describe the differences in these firms. He examined the relationship of diversification and the degree of synergy (between businesses) on the economic performance of the firm. Based on this examination, he specifies three types of synergy: operating synergy (created by links among units based on technical and/or market interdependence); managerial synergy (based on managerial talent and techniques); and financial synergy. 
Financial synergy resulted from "the enhanced ability to obtain external funding and ... capacity to deploy capital internally to the most promising of a wide range of divisional ventures" (Rumelt, 1974, p. 119). In his original sample, he found that most of the firms were attempting to achieve financial synergy (and to a lesser extent managerial synergy). Many of the firms had diversified into unrelated businesses. These firms (conglomerates) were characterized by a high degree of decentralization. Individual strategic business units (SBUs) were given a great deal of autonomy.

A large number of research efforts on the diversified firm have been based on Rumelt's (1974) ideas and research. Many of these empirical investigations supported the findings of Rumelt. Some studies, however, showed somewhat different results. In examining synergy, most of these studies of diversified firms did not determine if joint effects were actually achieved. It was assumed that synergy existed if there was relatedness between business units, e.g. in terms of markets or technologies. A number of research problems occurred because of the way these "linkages" were identified. In most cases the studies did not test if these linkages were successfully implemented by the firm. The major interest in most of these studies was to determine the type of diversification (based on Rumelt's classifications) and the overall impact this had on the performance of the firm.

\section{Interrelationships, value chain and competitive advantage}

The need to maintain a competitive advantage continues to be a primary driver in the diversified firm. The maturing firm must continually look for new ways to maintain its competitive advantage. Porter (1985) reports that one way to achieve competitive advantage is to coordinate activities between units. These are described as the opportunities available to the firm because it is diversified.

Porter (1985) suggests that many firms have not recognized and/or developed opportunities for resource sharing (joint effects). In Competitive Advantage: Creating and Sustaining Superior Performance, he devotes an entire section to a discussion of how the development of interrelationships between different business units can result in competitive advantage. Using the activities in the value chain, he suggests that resources and skills can be shared by different units. He also includes a discussion on why horizontal systems and processes are needed to achieve these interrelationships.

Jemison (1985, p. 174) notes that the "very nature of multibusiness firms creates substantial interdependencies among its different businesses/divisions". In terms of "lateral actions" Jemison indicates that interdependencies are related to the need for integration of activities that vary according to such factors as scope, complexity, and centrality to the unit.

In Ensign (1995) the issue of coordination in a multinational firm is examined. Based on this investigation and the growing consensus within the academic community, there is indication that coordination issues will become increasingly important as business environments become more competitive.

\section{Resource sharing and relatedness-empirical studies}

A review of the literature indicates a very limited number of empirical studies that examine the issues of interrelationships, resource sharing, relatedness, and the horizontal organization. Gupta and Govindarajan (1986) examined resource sharing in 58 SBUs. Their study, however, included only one hypothesis that was designed to test the actual sharing: resource sharing will make a greater contribution to an SBU's effectiveness with a low cost rather than a differentiation strategy. Results supported this hypothesis. The primary focus was to examine the role that two factors (organizational familiarity on the part of SBU managers and incentive systems controlling these managers) play in the effective management of resource sharing among SBUs.

Mahajan and Wind (1988) used the PIMS database to examine the relationship between synergy and profitability for six types of businesses. They used six questions on the PIMS survey instrument that were related to synergy. These questions were classified using Ansoff 's four categories of synergy (sales, operating, investment, and management synergy). Unfortunately, the use of only one or two questions to test each type of synergy is not a sufficient basis for drawing conclusions.

The measurement of performance for a single SBU may also be questioned. Based on a review of the literature, it is misleading to isolate the performance of a single SBU from the performance of the other SBUs that participate in sharing because some units will benefit more than others in this sharing process. It would be more correct to measure the performance of the total corporation, especially over a period of time. An ideal investigation would examine only those business units in which cooperation occurred between value-creating activities. 
Although the analysis and published report (Mahajan and Wind, 1988) seem to be less than adequate and contain inconsistencies, the ideas do merit further consideration. The questions on the PIMS survey could be helpful in designing a survey instrument to be used in an empirical investigation. Their study could be redesigned and repeated, especially since the current PIMS survey reportedly contains additional questions related to resource sharing.

Govindarajan and Fisher (1990) focused on the relationships between the control system, resource sharing, and competitive strategies. The primary emphasis is on the interactive effects of these three. The focus is on examining the different control systems used in different strategy and resource sharing situations. Their research therefore is of limited usefulness in the present study.

Very (1993) examined the relationship between operational and strategic relatedness and the success or failure of 26 diversification moves. Executives in seven large French industrial firms were interviewed. The format consisted of both structured and semi-structured phases. Results suggest that operational relatedness and managerial relatedness are linked with the success of diversification. Competitive structure and key success factors were used to measure managerial relatedness. Operational relatedness was a measure of the degree of sharing. Managers were also asked their perception of the impact of operational relatedness on competitive advantage. Although his study focused on diversification, it is quite helpful in informing the present study. A number of ideas could be used in an empirical investigation designed to examine resource sharing between value chain activities.

\section{UNDERSTANDING THE DIVERSIFIED FIRM Organization and interrelationships}

An understanding of the organization and interrelationships that exist in diversified firms is very important. Three general classifications are used to describe the organization of diversified firms. The matrix in Figure 1 shows these classifications. It has two dimensions. One dimension indicates the type of organization: vertical, horizontal, or portfolio. The other dimension includes the following characteristics: degree of centralization; size of central staff; type of decision making; type of control; and total firm perspective.

The matrix in Figure 1 can be extended to examine the interrelationships (between activities/units) which characterize each of these three types of organizations. This is summarized in the matrix in Figure 2. Looking at Figures 1 and 2 it is clear that the organization and interrelationships that exist in diversified firms can vary considerably. These have been presented to emphasize that the organizational context can determine a firm's motivation and ability to develop interrelationships that can result in overall competitive advantage.

At one extreme is the vertical organization, the traditional vertically-integrated firm. In this firm the degree of dependence may already be quite high. This has several implications for the development of resource sharing. From a positive standpoint, the organization is designed to transfer resources from one unit to another. However, because this is generally a one-directional (vertical) transfer of resources, this firm may not be equipped to identify and coordinate the mutual sharing of resources. Firms with a vertical organization may have a limited number of opportunities for significant value creation unless they undertake some changes in organization.

At the other extreme is the portfolio organization, the traditional conglomerate or unrelated diversified firm. A firm with this organization is decentralized. The business units are quite autonomous. There is a very limited amount of resource sharing between business units. In this organization, managers may not be willing or able to find or manage the interrelationships to achieve synergy. This diversified firm would need to make some important organizational changes over an extended period of time in order to develop interrelationships that can result in synergy.

The characteristics shown in Figure 1 (organization) and Figure 2 (interrelationships) suggest that a firm with a horizontal organization has the structure and mechanisms to encourage the successful development of interrelationships. It will be able to coordinate activities, encourage resource sharing, and establish interrelationships/interdependencies. Porter (1985) indicates that the characteristics of the horizontal organization can help a firm achieve competitive advantage. If a firm characterized as having either a vertical or portfolio organization did choose to develop interrelationships between units, it would need to incorporate some of the characteristics of a horizontal organization.

Some might argue that the horizontal organization does not exist. An examination of empirical studies, however, indicates that some firms have developed organizational systems and processes that can accommodate resource sharing. Although the necessity for such an organizational form is growing, in general, however, such firms are in the minority. 
An understanding of the horizontal organization helps to emphasize that organizational structure and processes are very important in developing interrelationships with the potential to achieve the goals of synergy and competitive advantage. Horizontal strategy is designed to coordinate activities and functions of different units. Although this paper is limited to an examination of interrelationships and horizontal strategy, horizontal structure is also of importance. Structural mechanisms and processes needed for achieving the successful management of interrelationships are investigated in a separate study (Ensign, 1998).

\begin{tabular}{|c|c|c|c|c|c|c|c|}
\hline & $\begin{array}{c}\text { Vertical } \\
\text { Organization }\end{array}$ & $\begin{array}{c}\text { Horizontal } \\
\text { Organization }\end{array}$ & $\begin{array}{c}\text { Portfolio } \\
\text { Organization }\end{array}$ & \multirow[b]{2}{*}{ Interrelationships } & $\begin{array}{c}\text { Vertical } \\
\text { Organization }\end{array}$ & $\begin{array}{c}\text { Horizontal } \\
\text { Organization }\end{array}$ & $\begin{array}{c}\text { Portfolio } \\
\text { Organization }\end{array}$ \\
\hline $\begin{array}{l}\text { Degree of } \\
\text { Centralization }\end{array}$ & high & varied & low & & dependence & interdependence & independence \\
\hline $\begin{array}{c}\text { Size of } \\
\text { Central Staff }\end{array}$ & large & medium & small & $\begin{array}{l}\text { Linkages in } \\
\text { Resource Sharing }\end{array}$ & $\begin{array}{l}\text { sequential } \\
\text { (chain) }\end{array}$ & $\begin{array}{l}\text { reciprocal/joint } \\
\text { (web/network) }\end{array}$ & $\begin{array}{c}\text { few/none } \\
\text { (hub and spoke) }\end{array}$ \\
\hline $\begin{array}{c}\text { Type of } \\
\text { Decision Making }\end{array}$ & hierarchical & lateral & autonomous & $\begin{array}{l}\text { Number of } \\
\text { Resources } \\
\text { Shared }\end{array}$ & $\begin{array}{c}\text { high } \\
\text { (one-directional) }\end{array}$ & varied & low \\
\hline $\begin{array}{l}\text { Type of } \\
\text { Control }\end{array}$ & $\begin{array}{l}\text { vertical } \\
\text { integration }\end{array}$ & $\begin{array}{l}\text { horizontal } \\
\text { coordination }\end{array}$ & $\begin{array}{l}\text { self-administered } \\
\text { (autonomous) }\end{array}$ & $\begin{array}{l}\text { Number of } \\
\text { Activities } \\
\text { Involved }\end{array}$ & high & varied & low \\
\hline $\begin{array}{l}\text { Total Firm } \\
\text { Perspective }\end{array}$ & high & highy/medium & low & $\begin{array}{l}\text { Focus of } \\
\text { Economies }\end{array}$ & operational & $\begin{array}{l}\text { operational/ } \\
\text { managerial } \\
\text { (synergistic) }\end{array}$ & financial \\
\hline
\end{tabular}

UNDERSTANDING INTERRELATIONSHIPS AND HORIZONTAL STRATEGY

As previously mentioned, much research on the diversified firm has centered on Rumelt's (1974) classification scheme and how related/unrelated entire business units are in a firm. Although this scheme has been helpful in understanding the types of diversification that exist in firms, it is not an appropriate way to examine interrelationships and resource sharing in the diversified firm. Development of successful interrelationships in diversified firms depends on the relatedness between specific activities rather than between entire units.

A study of interrelationships must focus on the relatedness of value chain activities in different business units. It must go beyond a study of the relatedness of whole business units in the diversified firm. It is necessary to examine the relatedness in activities where potential interrelationships can be developed. This can determine the potential for success in creating synergy and competitive advantage. The important thing is that synergy is not developed and achieved between entire units. Synergy is developed and achieved between particular activities - on an activity-by-activity basis.

\section{Interrelationships and horizontal strategy defined}

Two concepts are central to this study. The matrix in Figure 3 presents a way to illustrate and define the concepts of interrelationships and horizontal strategy. The commonly used words or terms found in the theoretical literature and research studies are presented in bold Italic letters. The headings used are: activity (value chain); choice; and goal.

Definitions for interrelationships and horizontal strategy can be based on this matrix:

- Interrelationships refer to: sharing of resources or skills in activities that have relatedness to achieve synergy.

- Horizontal strategy refers to: developing those interrelationships that create value to achieve competitive advantage.

This study focuses on horizontal strategy as a way of identifying and developing those interrelationships that can create value. For a diversified firm that seeks to develop 
interrelationships, horizontal strategies must fit the definition suggested above in order to create synergy and competitive advantage.

\section{Change in STRATEgic Thinking}

A number of changes are required to bring about a shift in strategic thinking. If the diversified firm seeks to develop horizontal strategies that can create value for the total corporation, it will require a new approach to planning. The role of corporate headquarters in the strategic planning process must change.

In the past, the traditional approach to strategic planning has resulted in two levels of strategy - business strategy and corporate strategy. The goal of business strategy has been to obtain superior performance and aboveaverage returns at the strategic business unit level. Business strategy is often called competitive strategy because it is viewed as the primary way to obtain competitive advantage.

Corporate strategy has been the overall plan for making the diversified firm worth more than the sum of its parts. It has generally focused on:

1) adding value by channeling investment into businesses that compete in industries with attractive structures; and 2) ensuring that the cost of entering a new business does not compromise future profits.

A third requirement of corporate strategy must be to organize and manage business units so that each can benefit from its link with the rest of the corporation. In many firms, corporate strategies have focused on the first two but have failed to develop the third (Clark, 1989).

If the third requirement of corporate strategy is to be taken seriously it means that a business within a diversified company must be better off because it is part of the corporate portfolio rather than operating independently. The question is, why is that business better off? There are a number of reasons. Corporate strategy can create value through: efficient capital allocation; diversifying risk; superior management; support services; expansion; restructuring; etc. One way of creating value that is often overlooked is that of synergy.

Corporate strategy must move beyond the idea that the primary way of creating synergy is the combination of related businesses (the buying and selling of businesses). Corporate strategy must center on creating value that is independent of business unit value. This means developing horizontal strategies that have goals and objectives that include the coordination of activities and the development of projects and programs that encourage the sharing of resources and skills. In an effort to promote adoption and dissemination of knowledge, Texas Instruments has a program to recognize when employees borrow technology existing elsewhere within the organization. The "Not invented here, but I did it anyway" award encourages sharing and results in efficient use and allocation of resources.

In diversified firms, corporate strategy can result in synergy when the central office builds a portfolio of businesses. But synergy can also be created when horizontal strategies are developed which encourage the sharing of activities or skills. Today's competitive environment may require firms to rethink the concept of synergy. Synergy can no longer be considered as just the fit (related or unrelated) of a firm's businesses. Synergy must emanate from relationships between the skills and activities in the various business units. Warner-Lambert for instance has business units that share some (though not all) skills and resources - operate in a globally integrated manner for particular areas of expertise.

Synergy must be based on tangible and intangible opportunities to create value. Synergy can be created when activities that have relatedness are shared. For a pharmaceutical firm, gelatin capsule technology may be common to several different types of drugs. In a diversified firm a business can potentially share any activity it performs with any other business in the same organization. There are many possibilities to share resources and skills. The critical decisions are related to what activities to coordinate in order to achieve competitive advantage. Clearly, the benefits of sharing must outweigh the costs of coordination - admittedly, something more easily envisioned than realized.

$\overline{\text { Figure } 3}$

Interrelationships and horizontal strategy

\begin{tabular}{c|c|c|c|}
\hline \multicolumn{1}{c}{ Activity } & \multicolumn{2}{c|}{ Choice } \\
\cline { 2 - 4 } Interrelationships & $\begin{array}{c}\text { Sharing of } \\
\text { resources or skills }\end{array}$ & $\begin{array}{c}\text { that have } \\
\text { relatedness }\end{array}$ & $\begin{array}{c}\text { to achieve } \\
\text { synergy. }\end{array}$ \\
\cline { 2 - 4 } Horizontal Strategy & $\begin{array}{c}\text { Developing } \\
\text { interrelationships }\end{array}$ & $\begin{array}{c}\text { that create } \\
\text { value }\end{array}$ & $\begin{array}{c}\text { to achieve } \\
\text { competitive } \\
\text { advantage. }\end{array}$ \\
\hline
\end{tabular}


Sharing activities can provide a number of operating benefits. But sharing activities may only result in competitive advantage under certain conditions. First, sharing must take place between activities that are a significant portion of total operating costs or assets. Second, sharing must reduce the cost of performing shared activities. This may be achieved through economies of scale and improved capacity utilization. Sharing may enhance product differentiation or help a firm move down the learning curve faster. Third, sharing must help differentiate a business from its competitors (Porter, 1985).

Sharing skills can also provide benefits. These benefits result when the technical or managerial expertise of one unit can be applied to another unit. This can depend on how related (similar or different) the business strategies of the units are that will share skills. However, sharing skills may only result in competitive advantage under certain conditions. First, similarities must be generic. This means similarities in: business strategy (low cost or differentiation); buyers or customers; operating configuration; or overall operating know-how. Second, sharing of skills must take place in core value-adding activities (important areas). Third, skills transferred or shared must be new or an improvement on those in the receiving unit. Sharing skills can significantly change the strategies and operations of a receiving unit (Clark, 1989).

Horizontal strategy is designed to create value for the total firm. Horizontal strategy does not replace the need for business strategy. The objective is to create value by strengthening a business unit's competitive position as well as that of the total firm. It provides a way for management to make the corporation worth more than the sum of its parts. Porter (1985) indicates that without it there may be no convincing rationale for diversification.

Ideally strategic issues will dominate decision making at all levels and in all functions. It is no longer sufficient for only top managers and headquarters to have a sense of where the company is headed. If all people at all levels understand horizontal strategy well enough, it will help to provide the flexibility and capability needed to obtain a sustainable competitive advantage. Dow Chemical has created an electronic database of projects and knowledgeable persons categorized by skill sets that serves as an active archive. At Dow, information-perhaps even knowledge - is at the disposal of employees throughout the organization. This system enables anyone in the organization to make connections and interact with others to develop interrelationships; employees can actively participate in forming horizontal strategies to generate synergies.

A change in strategic thinking means a different approach to planning. British Petroleum has "virtual team networks" for interactions/sharing between business units. A lateral planning process - characterized by shared decision making and collaboration-is needed. Managers who will be most affected by decisions should be involved in the planning process. The focus in planning must be on obtaining competitive advantage at the corporate level (through horizontal strategy) as well as at the business unit level. Corporate planning must also do a better job of integrating the planning process and implementation process. Strategy must be communicated with enough clarity to guide operating decision making throughout the company. Within the multinational telecommunication firm Ericsson, the designation of centers of excellence serves to alert those throughout the diversified organization, that there are specialists to turn to for solutions to particular problems. Drawing attention to areas of expertise that can be drawn from-or joined for collaboration-creates value and efficiency. It also creates an awareness of strategy that permeates the organization.

\section{Strategic Formulation Process: Assessments of Competitive Advantage ANd Synergy}

In a diversified firm, success in accomplishing joint effects must begin with a proactive and explicit approach to strategy formulation. A corporate level approach is needed. This approach is based on horizontal strategies designed to:

- create value at the corporate level;

- support (including funding) coordination projects between activities; and

- identify interrelationships with the greatest potential for competitive advantage.

Since the number of possible interrelationships may be high, the major task is to identify those that will create the greatest value for the total firm.

This paper calls for a strategic formulation process that consists of a series of assessments for a potential interrelationship. The process is sequential. It should be possible to evaluate a potential interrelationship as assessments are made. For a few assessments, a sample test (labeled Test 1) is included in the Appendix. Since this strategic formulation process and the assessments were 
designed for this study, the ideas in this section should be considered exploratory. They could be further expanded and validated in another study.

During the strategic formulation process, assessments of potential interrelationships are made to determine: value that can be created; and relatedness that exists. Beginning with value, an assessment for competitive advantage is made to determine the similarities and differences that exist in the units where resource sharing would occur. Assessment for competitive advantage is made on:

- business strategy-relatedness;

- importance-relatedness; and

- competitive-relatedness.

If the businesses to share the activity have high relatedness, value may be created that can result in competitive advantage.

It is also necessary to examine the relatedness between the businesses and specific activities in those businesses where the resource sharing would occur. Since sharing would involve operational and managerial resources, assessment for synergy is made on:

- operations/functions-relatedness;

- managerial-relatedness; and

- historical/cultural-relatedness.

At the end of these assessments, it should be possible to define the hoped for joint effects in the form of a horizontal strategy.

\section{Assessments for competitive advantage}

Business strategy-relatedness. An assessment of business strategy is made to determine if the competitive strategies of the units are similar. This is critical because business strategy influences how competitive advantage is achieved. Units with a cost leadership (low cost) strategy will derive an advantage from operating/manufacturing synergy primarily in upstream activities. Units with a differentiation strategy will derive an advantage from marketing/sales synergy - primarily in downstream activities. It is easy to imagine how opposing business strategies could result in substantial conflicts. Even if activities in business units are related in terms of technology or processes, strategic differences could prohibit value creation and conceivably lead to achievement of negative synergies (value destruction).

Units with different strategies will also have different benefits from sharing resources. First, in a unit pursuing a cost leadership strategy, resource sharing is intended to facilitate scale economies and reduce costs. In general, the benefits are easier to identify and may be easier to achieve. Potential benefits may also be higher. Second, in a unit pursuing a differentiation strategy, resource sharing is intended to contribute to the uniqueness of an activity. The benefits from resource sharing are harder to identify and may be more difficult to achieve. Resource sharing, in fact, could have a negative impact by reducing the flexibility needed to compete in an environment that demands creativity and quick changes.

A comparison of the business level strategies for each of the units may provide an indication of potential competitive advantage. Very (1993,p. 83) states that strategic similarity may even be a "surrogate measure of managerial relatedness". It is critical that the units to share resources have the same competitive strategy.

Importance-relatedness is the second step in screening a potential interrelationship. When considering an interrelationship, it is necessary to know how much of the total product or business budget is spent on the activity to be shared by each of the units. This amount should be significant enough to justify the costs of coordination. Because of the costs involved, coordination may be possible in only certain cases, e.g. those that are centers for sourcing, high profit, or large volume markets. This amount will vary for each activity and each unit within the firm. As part of this assessment, it may also be important to know the total assets currently invested in performing the activity. Finally, it is important to calculate the cash flows for the activity in each of the units.

Importance-relatedness should also determine how critical the need is for each unit to change or improve its performance in this activity. If there is a perceived need for change, there may be a greater willingness to participate in establishing the interrelationship (joint interest). Though a crisis is not necessary to mobilize the necessary personnel for resource sharing, some sense of urgency or at a minimum, acknowledging "room for improvement" sets the tone for interrelationships leading to synergy. Interviews with various personnel at Ericsson Research Canada revealed that impetus for sharing may come from a variety of levels, but those interrelationships generated at lower levels in the hierarchy tend to be more successful than the sharing of activities dictated by upper management. To examine importance-relatedness, Test 2 is found in the Appendix.

Competitive-relatedness is the third area for examining a potential interrelationship. 
It is essential to determine the similarities and differences in the competitive structure of the industry in each of the businesses where resources would be shared. This would indicate if the units are similar or different in terms of: primary competitors; market share; rivalry between competitors; etc. (in the Appendix, Test 3 examines competitive structure). Differences in the business environments (environmental turbulence) might also be examined.

This assessment should determine the factors that are specific to each business. A comparison of these factors should be made for the business units that would be involved in sharing resources. The concepts of core competence and key success factors could be used to determine the distinctive competence and resources available in each unit.

Finally, this assessment should determine the advantage to the firm of pursuing this interrelationship based on the difficulty of matching the relationship by competitors. This is generally related to the overall cost of coordinating activities or making operational and managerial compromises. For example, a competitor may face higher or lower costs in matching the interrelationship. These barriers to entry may determine the sustainability of the competitive advantage resulting from developing this interrelationship.

\section{Assessments for synergy}

These assessments are part of a continuing effort to examine the interrelationship that has been screened for competitive advantage. During the strategic formulation process, an examination should be made to determine if the businesses to share resources have organizational relatedness. Since organizational factors can have a strong impact on interrelationships, these factors will have an impact on achieving synergy.

Operations/functions-relatedness. Operations often reflects tangible physical assets which may contribute to decreased investment requirements or decreased operating costs if resources or skills are shared or transferred between units. Each of these areas-operations and functions-has specific assets (skills or resources) that can be assessed to determine the contributions from sharing with another unit. Ansoff (1988) suggests four categories of assets that each will have: facilities and equipment; personnel skills; organizational capabilities; and management capabilities.

The activity where resources or skills will be shared should be assessed for overall relatedness (similarities and differences) on these four categories. This will help to determine if joint effects can be attained. An assessment of these four areas can determine the contributions/capabilities (strengths) that a unit can provide as well as the deficiencies (weaknesses) that exist. It will provide an understanding of the kinds of operating or functional problems faced by each unit in performing the activity. It will also generate knowledge on the most important operating or functional capabilities needed by each unit.

Managerial-relatedness is very important to determine the potential success of sharing between two units. Managers have different backgrounds - different training, professional experiences, and current responsibilities. It is important to determine the kinds of experiences managers have had that would have an impact on their ability to be involved in resource sharing or managing a coordination project.

It is important to determine the types of strategic, organizational, and operational problems that have been faced by a manager. The type of decision process used will be linked to the organizational and environmental situation that each unit has confronted. The particular situation may or may not be relevant (related) to the context where sharing would occur.

Finally, it is important to determine if the managers who would be involved in sharing have the time available to devote to these new coordination tasks. Are they already fully committed? If so, is there any way to relieve them so they could take on new responsibilities?

Historical/cultural-relatedness. An assessment of historical/cultural-relatedness is important as an indication of the overall organizational relatedness (heritage) between the two businesses. In a diversified firm, units to share an activity may have quite different diversification histories. Research studies have found that how a unit was developed (internal diversifier) or acquired (acquisitive diversifier) can have an impact on overall congruence (Pitts, 1980). Units can have different corporate cultures. A cultural web could be designed to show the relatedness of the two units (Clarke, 1987). This final assessment can also be used to turn up other similarities and differences that may be specific to the particular activity where sharing would occur.

\section{CONCLUSION}

This paper has sought to show that synergy is not simply a phenomenon that occurs at the corporate level-between whole business units - but is best viewed as resulting from 
specific instances of resource or activity sharing between segments/portions of different business units. The perspective put forth in this paper, however, is not contradictory but rather a refinement of existing ideas. Previous conceptualizations of synergy have failed to emphasize that it is not business units in their entirety but rather it is particular elements - individual activities or resources - within them that combine to create value for a conglomerate. For a given business unit, some resources and activities may be worth sharing while others may not be. Further, whether a resource or activity creates value through collaboration is dependent on the business unit for which the sharing is being considered. That is, business units must be looked at relative to one another when exploring if interrelationships will lead to the creation or destruction of value. Determining which resources and activities are worth sharing - and with which business units - is the problem. Sorting through this question regarding the costs of coordination and the benefits of collaboration can be aided, it is hoped, by the concepts put forth in this paper.

The perspective proposed here should serve to complement existing conceptualizations of synergy. In this paper, steps have been taking toward outlining the fundamentals for joint effects between activities and resources in different business units. The potential of interrelationships must be identified and then systematically evaluated. Areas for collaboration can be identified by considering the activities and resources in the business unit that create value for the business unit and could possibly contribute to another business unit's value creation process. Whether synergy can likely be realized should be based on an honest assessment by management in the business units of those being considered for collaboration. For the business units concerned with sharing a particular activity or resource, an examination of business strategy-relatedness (using Test 1 in the Appendix), importance-relatedness (using Test 2 in the Appendix), and competitive-relatedness (using Test 3 in the Appendix) should be performed.

It is important to note that the probability of developing interrelationships for synergy is not simply a matter of paper and pencil calculations but is heavily dependent on implementation concerns. That elements brought together which should in theory lead to value creation may be defied by reality should not be surprising. Activities and resources of different business units cannot be merely brought together but must be properly combined.

Consideration must be given to individual actors and their reactions anticipated. If one business unit is given charge of an activity, those in the business unit losing authority can be expected to experience anxiety or resentment. The mixing of employees responsible for different activities and rotation among business units can help to both identify and realize advantages of interdependencies. Management support must be more than mere edict, the success of horizontal strategies is contingent on systems that contribute to reaching goals.

While interrelationships will not emanate without cultivation, some interrelationships should materialize in a natural, perhaps intuitive, manner. Any appraisal of horizontal strategy must take into account existing context and organizational history. That is not to say that interrelationships should be effortless, some work and difficulty is to be expected. In fact, it is unlikely that those interrelationships that are easily found and advanced would lead to sustainable competitive advantage. It is those interrelationships that are not obvious that may be especially worth pursuing. Creating interdependencies which competitors cannot readily decipher or imitate is the objective. A horizontal strategy should be constructed with erecting barriers to competition in mind.

The inspection of interrelationships and installation of horizontal strategy as sketched out in this paper may be assisted by borrowing templates from the value chain analysis approach or resource-based view of the firm. Employing frameworks such as these in concert with the techniques and tools discussed in this paper should prove fruitful in recognizing and orchestrating the necessary components of synergy. Implications for scholars and practitioners are largely quite similar. Whether one is trying to study interdependencies or actualize interrelationships that comprise horizontal strategy - synergy must be decomposed into its constituent parts.

\section{Application Questions}

1) Using Test 1 in the Appendix, answer the questions for business units in your organization. What insights are gained into the strategic similarities and differences between units in your organization? Where do possible synergies exist?

2) Using Test 2 in the Appendix, what activities in your organization are candidates for resource sharing?

3) Using Test 3 in the Appendix, what are the similarities and differences between units in your organization? What role has the history (evolution) of the units played in their current array of resources and skills? 


\section{REFERENCES}

Ansoff, H.I. (1965) Corporate Strategy: An Analytic Approach to Business Policy for Growth and Expansion, McGraw-Hill, New York, NY.

Ansoff, H.I. (1988) The New Corporate Strategy, Wiley, New York, NY.

Chakravarthy, B.S. and Lorange, P. (1991), Managing the Strategy Process: A Framework for a Multibusiness Firm, Prentice-Hall, Englewood Cliffs, NJ.

Clark, R. (1989) "Horizontal hook-up”, CA Magazine, 122(7): 24-33.

Clarke, C.J. (1987) “Acquisitions - techniques for measuring strategic fit”, Long Range Planning, 20(3): 12-18.

Davis, P.S., Robinson R.B. Jr, Pearce, J.A. II and Park, S.H. (1992), "Business unit relatedness and performance: a look at the pulp and paper industry", Strategic Management Journal, 13(5): 349-61.

Ensign, P.C. (1995) "The multinational corporation as a coordinated network: organizing and managing differently", paper presented at Academy of Management Conference, Organizational Dimensions of Global Change: No Limits to Cooperation, Cleveland, $\mathrm{OH}$.

Ensign, P.C. (1998) “Interdependence, coordination, and structure in complex organizations: implications for organization design", Mid-Atlantic Journal of Business, 34(1): 5-22.

Govindarajan, V. and Fisher, J. (1990) "Strategy, control systems, and resource sharing: effects on business-unit performance", Academy of Management Journal, 33(2): 259-85.

Gupta, A.K. and Govindarajan, V. (1986) "Resource sharing among SBUs: strategic antecedents and administrative implications", Academy of Management Journal, 29(4): 695-714.

Hill, C.W.L. and Hoskisson, R.E. (1987) "Strategy and structure in the multiproduct firm", Academy of Management Review, 12(2): 331-41.

Hofer, C.W. and Schendel, D. (1978) Strategy Formulation: Analytical Concepts, West Publishing, St Paul, MN.

Jemison, D.B. (1985) “The role of the division general manager in corporate strategic management", in Lamb, R. and Shrivastava, P. (Eds), Advances in Strategic Management, JAI Press, Greenwich, CT, pp. 163-79.

Kay, N.M. (1982) The Evolving Firm: Strategy and Structure in Industrial Organization, St Mar- tin's Press, New York, NY.

Kogut, B. (1983) "Foreign direct investment as a sequential process", in Kindleberger, C.P. and

Audretsch, D.B. (Eds), The Multinational Corporation in the 1980s, MIT Press, Cambridge, MA, pp. 38-56.

Mahajan, V. and Wind, Y. (1988) "Business strategy does not always pay off", Long Range Planning, 21(1): 59-

65.

Miller, D. (1990) The Icarus Paradox: How Exceptional Companies Bring about Their Own Downfall, HarperCollins Publishers, New York, NY.

Nayyar, P.R. (1992) "On the measurement of cor- porate diversification strategy: evidence from large US service firms", Strategic Management Journal, 13(3): 219-35.

Pitts, R.A. (1990) “Toward a contingency theory of multibusiness organization design", Academy of Management Review, 5(2): 203-10.

Porter, M.E. (1980) Competitive Strategy: Techniques for Analyzing Industries and Competition, Free Press, New York, NY.

Porter, M.E. (1985) Competitive Advantage: Creating and Sustaining Superior Performance, Free Press, New York, NY.

Porter, M.E. (1987) "From competitive advantage to corporate strategy", Harvard Business Review, 65(3): 43-59.

Rumelt, R.P. (1974) Strategy, Structure and Economic Performance, Division of Research, Harvard University, Cambridge, MA.

Teece, D.J. (1980) "Economies of scope and the scope of the enterprise", Journal of Economic Behavior \& Organization, 1(3): 223-47.

Very, P. (1993) "Success in diversification: building on core competencies", Long Range Planning, 26(1): 80-92. 
APPENDIX

Test 1: business strategy-relatedness

Activity

Unit 1 Unit 2

Strategy Strategy

Identify the major strategy being pursued for each of the units. Although this discussion concerns a pair of units, the test is also applicable to more than two units.

In most cases, it is possible to identify the unit strategy as:

1) Low cost strategy (cost leadership). The dominant focus is to achieve the lowest cost relative to competitors. This can occur by:

- aggressive construction of efficient-scale facilities;

- vigorous pursuit of cost reductions from experience;

- tight cost and overhead control;

- avoidance of marginal customer accounts; and

- cost minimization in areas like R\&D, service, salesforce, advertising, etc. (Porter, 1980).

2) Differentiation strategy. The primary focus is to create something that is perceived as unique through the introduction of superior product features, customer service, improved image and/or performance. This can be done by:

- pioneering/innovation - creating something perceived industry-wide as being unique;

- marketing/sales ability; and

- quality leadership (Miller, 1990).

Business strategy influences:

1) the activities or factors which drive synergy;

2) the benefits derived from sharing resources; and

3 ) the way competitive advantage is achieved.

Since business strategy can influence competitive advantage, it is important to understand where value can be created. Table AI provides examples to show how different factors and activities influence synergy.

\section{Test 2: importance-relatedness}

Activity

Unit 1 Unit 2

This test is designed to determine if this activity is a major source of value creation in each unit.

1) How much (percentage) of the total product/business budget is spent on this activity? Unit 1 Unit 2

2) What is the total dollar amount of assets currently invested in this activity/business? Unit 1 Unit 2

3) How critical is the need for a change/ improvement in this activity? Unit 1 Unit 2

4) Will coordination of resource sharing make a contribution to your unit? Unit 1 Unit 2 
Test 3: competitive-relatedness

Competitive structure

Activity

Unit 1 Unit 2

Indicate if the units above are similar/ different in terms of:

Primary competitors

Market share

Rivalry between competitors

Bargaining power suppliers/buyers

Concentration of competitors

Differentiation possibilities

Scale economies

Concentration of demand

Degree of globalization

Degree of maturity

Technological intensity

Marketing intensity

Labor intensity

$\begin{array}{rllll}\text { Similar } & & & & \text { Different } \\ 1 & 2 & 3 & 4 & 5 \\ 1 & 2 & 3 & 4 & 5 \\ 1 & 2 & 3 & 4 & 5 \\ 1 & 2 & 3 & 4 & 5 \\ 1 & 2 & 3 & 4 & 5 \\ 1 & 2 & 3 & 4 & 5 \\ 1 & 2 & 3 & 4 & 5 \\ 1 & 2 & 3 & 4 & 5 \\ 1 & 2 & 3 & 4 & 5 \\ 1 & 2 & 3 & 4 & 5 \\ 1 & 2 & 3 & 4 & 5 \\ 1 & 2 & 3 & 4 & 5 \\ 1 & 2 & 3 & 4 & 5\end{array}$

This chart is adapted from Very (1993).

$\overline{\text { Table Al }}$

Low cost and differentiation factors driving synergy

\begin{tabular}{ll}
\hline Factors driving synergy & Possible synergies \\
\hline Low cost & Rationalization of operations \\
Capacity & $\begin{array}{l}\text { Access to new markets or distribution channels to } \\
\text { achieve critical mass }\end{array}$ \\
Economies of scale & $\begin{array}{l}\text { Access to skills/management to build on existing } \\
\text { learning }\end{array}$ \\
Learning effect & Access to lower cost inputs \\
Factor costs & Access to new operating locations \\
Logistics & Access to proprietary designs \\
Technology & Joint R\&D facilities \\
& Lower overhead with improved systems \\
Differentiation & Better selling terms \\
Greater product range & Ability to close out competition \\
Fill product gaps & Brand switching benefits \\
Extend product range & Use other products to enhance prices or volumes \\
Strong brand images & Additional sales through established relationships and \\
Customer base (geographic penetration) & channels \\
& Increased prices or volumes \\
Logistics (administrative service) & Increased prices or volumes \\
Superior quality (performance) & \\
Source: Adapted from Clarke (1997) &
\end{tabular}

